\title{
TRIBUN SEPAKBOLA BERBASIS ALAM SEBAGAI TEMPAT BERAKTIVITAS PUBLIK DI KELURAHAN KALIANYAR
}

\author{
Christopher Tjandrawira ${ }^{1)}$, Petrus Rudi Kasimun ${ }^{2)}$
}

1)Program Studi S1 Arsitektur, Fakultas Teknik, Universitas Tarumanagara, Christophertjandrawira@gmail.com

2)Program Studi S1 Arsitektur, Fakultas Teknik, Universitas Tarumanagara, Rudi.kasimun@gmail.com

\begin{abstract}
Abstrak
Sebagai salah satu kelurahan terpadat di Jakarta, Kalianyar mengalami permasalahan sosial dan kesehatan karena kurangnya ruang hijau yang menyebabkan kurangnya ruang untuk beraktivitas dan munculnya berbagai macam penyakit. Kalianyar sebenarnya memiliki sebuah lapangan sepakbola yang dapat digunakan sebagai pengganti dari sebuah ruang hijau, namun hingga sekarang, tidak pernah dimanfaatkan akibat lokasinya yang tersembunyi dan eksklusifitas lapangan. Proyek ini bertujuan untuk memanfaatkan lapangan tersebut menjadi sebuah tempat ketiga dengan nuansa alam yang dapat mewadahi aktivitas masyarakatnya. Sebuah lapangan, yang merupakan sekadar ruang, tidak akan seketika menjadi sebuah "tempat ketiga". Sebuah desain diperlukan, yang dalam kasus ini, sebuah tribun yang menjadi, pendukung, dan penghubung pada lapangan, untuk menghidupkan dan memberi aktivitas pada lapangan kosong tersebut agar dapat menjadi sebuah tempat beraktivitas. Tribun, secara umum merupakan bangunan yang eksklusif oleh penggemar sepakbola, sehingga diperlukan analisis yang berfokus pada aktivitas dan material agar desain dapat menjadi ruang terbuka hijau bagi seluruh masyarakat Kalianyar. Metode yang digunakan merupakan metode perancangan arsitektur dengan pendekatan Arsitektur ekologi. Hasil yang didapat berupa tribun bambu. mengingat minimnya ruang dan biaya, penggunaan material bambu dapat menjadi solusi karena dapat tumbuh dengan cepat, ekonomis serta dapat memberikan ruang hijau secara alami kepada lingkungan.
\end{abstract}

\section{Kata kunci: Aktivitas publik; Ruang terbuka hijau; Tribun}

\begin{abstract}
As one of the most populous sub-districts in Jakarta ,Kalianyar is experiencing social and health problems due to lack of green space which causes lack of space for activities and the emergence of various diseases. Kalianyar actually has a soccer field that can be used as a substitute for a green space, but until now, it has never been used because of its hidden location and exclusivity. This project aims to utilize the field to become a third place with natural nuances that can accommodate the activities of the community. A field, which is merely space, will not immediately become a "third place". A design is required, which in this case, a stands that support and connect the field, to give activities to the empty field so it can be a place of activity. The Tribune, in general, is an exclusive building to football fans, so an analysis that focuses on activities and materials is needed so that the design can be a green open space for the whole society of Kalianyar. The method used is architectural design method with an ecological architecture approach. The results obtained is bamboo tribune. given the lack of space and cost, the use of bamboo material can be a solution because it can grow quickly, economically good and can provide a natural green space to the environment.
\end{abstract}

\section{Keywords: Green open space; Public Activity; Tribune}




\section{PENDAHULUAN}

\section{Latar belakang}

Jakarta merupakan sebuah kawasan dengan jumlah RTH yang sangat sedikit, Pemerintah Kota DKI Jakarta (2011). pada "Rencana tata ruang DKI Jakarta 2011-2030". mengabarkan Jakarta hanya memiliki 9,9\% RTH dengan target Pemerintah yaitu 30\% RTH di 2030. Dampak yang sering dirasakan dengan kurangnya Ruang terbuka berpengaruh pada sebuah pola hidup yang terbentuk di Jakarta yang mengedepankan rekreasi ke sebuah mall, meningkatnya angka penyakit yang ada baik akibat masalah sanitasi maupun mental. Sebagai salah satu kelurahan terpadat di Jakarta, Kalianyar, memiliki berbagai permasalahan yang dicantumkan di atas, baik masalah sosial dan kesehatan yang diakibatkan oleh kurangnya ruang hijau, padatnya bangunan sehingga menyebabkan kurangnya ruang untuk beraktivitas senggang dan munculnya berbagai macam penyakit (Hadiyanto, 2020). Padahal, Kalianyar memiliki sebuah lapangan sepakbola yang dapat digunakan sebagai pengganti dari sebuah ruang hijau, namun hingga sekarang, tidak pernah dimanfaatkan akibat lokasinya yang tersembunyi dan eksklusifitasnya lapangan terhadap penggemar sepakbola.

\section{Rumusan permasalahan}

a. Bagaimana menghadirkan sebuah tribun sepakbola dapat menjadi sebuah sarang rekreasi atau ruang publik umum.

b. Bagaimana sebuah tribun sepakbola dapat dibangun menjadi sebuah bangunan yang menyatu dengan alam.

\section{Tujuan}

Proyek ini bertujuan menghadirkan sebuah solusi desain dalam bentuk program dan urban guidelines yang dapat digunakan untuk membangun tribun sepakbola yang dapat berfungsi sebagai ruang publik hijau, dengan memanfaatkan kebutuhan tribun oleh lapangan agar terjadinya sebuah desain yang tergabung dan fleksibel fungsinya sehingga dapat tercipta sebuah ruang yang efektif baik secara biaya dan besaran ruang.

\section{KAJIAN LITERATUR}

\section{Ruang dan tempat}

Untuk mengenal apa itu ruang ketiga, sebelumnya akan dibahas dulu mengenai komponen penting dari ruang ketiga itu sendiri, yaitu ruang, dan apa perbedaannya dengan tempat. Berikut akan dibahas mengenai tempat dan ruang menurut situs Pps.org (2016) dalam artikelnya yang berjudul "You Asked We Answered: 6 Examples of what makes a great public space", Space adalah area atau bentangan berkelanjutan yang bebas, tersedia, atau tidak dihuni sedangkan place sebagian dari ruang yang tersedia atau dirancang untuk atau digunakan oleh seseorang.

\section{Tempat ketiga}

Menurut Oldenburg (1991) pada bukunya "The Great good Place", Tempat ketiga adalah "jangkar" kehidupan komunitas dan memfasilitasi dan mendorong interaksi yang lebih luas dan lebih kreatif. 


\section{Karakteristik Tempat ketiga}

Menurut Oldenburg third place memiliki 8 karakteristik,

a. Neutral

b. Yang berarti tidak perlu ada tujuan tertentu yang terikat terhadap pengunjung yang akan datang.

c. Leveled

d. Yang berarti tidak memandang status, semua berhak untuk mengunjungi dan menggunakan fasilitas dari third place.

e. Conversation is the main activity

f. Sebuah sarana third place harus mengutamakan interaksi sosial sebagai tujuan utama.

g. Accessibled and accommodated

h. Fasilitas yang ada harus terbuka, mengutamakan kenyamanan manusia yang ada di dalamnya.

i. Have regulars

j. Sebuah Third Place harus memiliki sejumlah pengunjung tetap untuk menjaga keberlangsungan dan jalannya tempat tersebut.

k. low profiled

I. Third Place sebaiknya, baik dalam program dan fisiknya bersifat umum, tidak didesain secara khusus pada suatu program dan aktivitas tertentu.

$\mathrm{m}$. The mood is playful

n. Sebagai sebuah tempat yang bukan tempat tinggal dan tempat kerja, sebuah third place sebaiknya menanggalkan sifat-sifat yang dimiliki sebuah tempat kerja dan tempat tinggal dan lebih mengarah ke aktivitas-aktivitas yang melepaskan suasana terstruktur dan teratur yang ada di tempat tinggal dan tempat kerja.

o. A home away from home

p. Sebuah third place sebaiknya memiliki unsur kenyamanan dan intimasi yang dimiliki oleh sebuah tempat tinggal.

\section{Bentuk-Bentuk Third Place}

Berdasarkan hasil riset Jeffres (2009) Third Place dapat berbentuk program-program dan tempat sebagai berikut :

a. Community Centers,

b. Coffee Shops And Cafes,

c. Markets,

d. Barber And Beauty Shops,

e. Churches,

f. Schools,

g. Libraries,

h. Parks And Other Places Allowing For Outdoor Recreation,

i. Events Like Neighborhood Parties, Block Parties, Cookouts, Barbecues, Town Meetings, Bingo, And Various Media

\section{Ruang terbuka Hijau}

Istilah "ruang terbuka kota" dapat menggambarkan banyak jenis area terbuka. Myers (1975) pada bukunya "Decision Making in Allocating Metropolitan Open Space: State of the Art" menyatakan bahwa, "Ruang terbuka kota adalah sumber daya alam dan budaya, yang identik dengan 'tanah yang tidak digunakan' maupun 'taman dan tempat rekreasi." Sedangkan Francis et.al. (2012) pada buku "Creating sense of community: The role of public space" menyebutkan, "Ruang terbuka adalah area tanah atau air dengan permukaannya yang terbuka ke langit, secara sadar diperoleh atau diatur secara publik untuk melayani fungsi konservasi dan 
pembentukan kota selain memberikan peluang rekreasi." Dari sudut pandang lain, ruang publik secara umum didefinisikan sebagai tempat pertemuan atau berkumpul yang ada di luar rumah dan tempat kerja yang umumnya dapat diakses oleh anggota masyarakat, dan yang menumbuhkan interaksi dan peluang penduduk untuk kontak dan kedekatan. Definisi ini menyiratkan tingkat interaksi masyarakat yang lebih tinggi dan menempatkan fokus pada keterlibatan publik dibandingkan kepemilikan atau pengelolaan publik.

\section{Manfaat Ruang terbuka hijau sebagai ruang ketiga}

Menurut Fuller et.al. (2007), di bukunya. "Psychological benefits of greenspace increase with biodiversity" Manfaat yang diberikan ruang terbuka perkotaan kepada warga dapat dibagi menjadi empat bentuk dasar; rekreasi, ekologi, nilai estetika, dan dampak kesehatan yang positif.

a. Rekreasi

Rekreasi di ruang terbuka kota dapat mencakup rekreasi aktif (seperti olahraga yang diorganisir dan latihan individu) atau rekreasi pasif, yang mungkin hanya memerlukan berada di ruang terbuka. Penelitian menunjukkan bahwa; ketika ruang terbuka menarik dan mudah diakses, orang lebih cenderung terlibat dalam aktivitas fisik.

b. Ekologi

Konservasi alam di lingkungan perkotaan memiliki dampak langsung pada manusia karena alasan lain juga. Bureau of Municipal Research (1971) menyatakan bahwa "kesadaran populer akan keseimbangan alam, proses alam, dan tempat manusia dalam dan pengaruhnya pada alam, yaitu " kesadaran ekologis " itu penting. Di luar manfaat alammanusia ini, ruang terbuka perkotaan juga berfungsi mempromosikan keanekaragaman hayati dan menyediakan rumah bagi spesies alami di lingkungan yang tidak dapat dihuni karena pembangunan kota.

c. Estetika

Nilai estetika ruang terbuka perkotaan sangat jelas. Orang-orang senang melihat alam, terutama ketika alam tidak tersedia dengan cukup, seperti halnya di lingkungan perkotaan. Thompson (2013) di jurnalnya "Activity, exercise and the planning and design of outdoor spaces" menyatakan bagaimana lingkungan yang menarik berkontribusi pada sikap positif dan norma sosial yang mendorong nilai-nilai berjalan dan masyarakat.

d. Kesehatan

Organisasi Kesehatan Dunia menganggap ruang hijau perkotaan penting bagi kesehatan manusia. Area-area ini memiliki dampak positif pada kesehatan mental dan fisik. Ruang terbuka perkotaan sering termasuk pohon atau semak-semak lainnya yang berkontribusi pada suhu sedang dan mengurangi polusi udara (Shishegar, 2013). Persepsi kesehatan umum lebih tinggi pada populasi dengan persentase ruang hijau yang lebih tinggi di lingkungan mereka (Maas et.al., 2006). Akses ruang terbuka perkotaan juga secara langsung terkait dengan pengurangan dalam prevalensi dan keparahan penyakit kronis yang dihasilkan dari gaya hidup yang menetap, untuk peningkatan kesejahteraan mental, dan pengurangan dampak kesehatan masyarakat dari perubahan iklim (Kingsley, 2019).

\section{METODE}

\section{Metode perancangan}

Proses Desain menggunakan metode perancangan arsitektur dengan pendekatan arsitektur ekologis dengan rangkaian proses desain sebagai berikut berdasarkan nomor urut.

a. Studi literatur

Mengenai tempat ketiga dan ruang terbuka hijau.

b. Studi preseden

Sebagai pembanding dan untuk mencari faktor kesuksesan sebuah ruang terbuka hijau. 
c. Pengamatan lokasi perancangan

Untuk mencari potensi dari karakter lokasi, data yang dicari adalah; Sejarah lokasi perancangan, Peta penggunaan lahan dan solid void, Profesi dan aktivitas masyarakat di lokasi.

d. Studi material

Berdasarkan estimasi daya tahan, biaya, dan dampaknya terhadap lingkungan.

e. Pembentukan program desain

Berdasarkan hasil studi literatur, preseden, dan lokasi perancangan.

f. Studi lokasi tapak, bentuk tapak, dan massa bangunan

Untuk menentukan bentuk yang ideal baik secara visual dan fungsi.

g. Penyusunan program desain

Berdasarkan keterkaitan dan jangkauan antar ruang.

h. Studi ruang dalam

Penambahan furniture dan finishing dalam bangunan.

\section{Metode pengambilan data}

Metode pengambilan data menggunakan metode kualitatif deskriptif. Pada langkah pertama, Penulis melakukan observasi langsung ke dalam daerah perancangan untuk mendata jenisjenis pekerjaan, aktivitas yang ada serta bentuk bangunan yang ada dan apa pengaruhnya di Kelurahan Kalianyar guna mencari kekurangan baik potensi kegiatan positif yang dapat terjadi di lokasi pengamatan. Pada langkah kedua, Penulis menggambarkan situasi melalui kalimat deskriptif untuk diolah lebih lanjut menjadi sintesis atau konsep.

\section{DISKUSI DAN HASIL}

\section{Hasil Pengamatan lokasi perancangan}

Berdasarkan pengamatan pribadi, penduduk Kalianyar mayoritas bekerja sebagai buruh jahit dan pedagang kaki lima keliling dan selayaknya sebuah kelurahan dan pemukiman padat, Kalianyar memiliki lahan yang terbatas, sehingga mengakibatkan kurangnya ruang-ruang publik ataupun ruang hijau yang diperlukan sebuah pemukiman. Pengamatan dan pendataan pribadi yang dilakukan memperlihatkan bahwa kelurahan ini tidak memiliki satupun ruang publik terbuka di dalam kelurahannya, dimana ruang publik terbuka yang ada merupakan RPTRA Krendang, yang berjarak sekitar 1 kilometer dari batas utara Kalianyar, yang melebihi batas jarak pejalan kaki optimal.

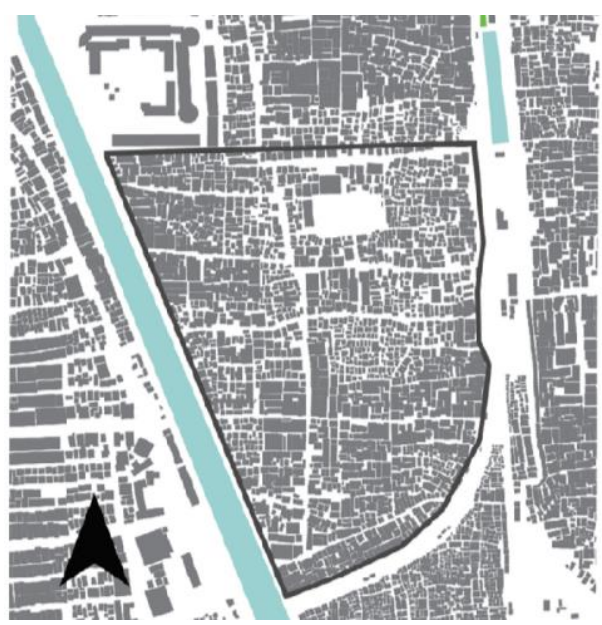

Gambar 1. Peta Solid void Kalianyar memperlihatkan padatnya bangunan Sumber: Penulis, 2020 
Masyarakat Kalianyar beradaptasi dengan kurangnya ruang terbuka pada lingkungannya dengan cara menjadikan jalan sebagai ruang terbuka dan ruang umum yang ada, hasil pengamatan menunjukan bahwa jalanan menjadi sebuah ruang bermain untuk anak-anak, ruang ngobrol dan bertemu untuk semua kalangan, dan juga menjadi tempat mencari nafkah untuk berbagai pedagang yang tinggal di sekitar lokasi.

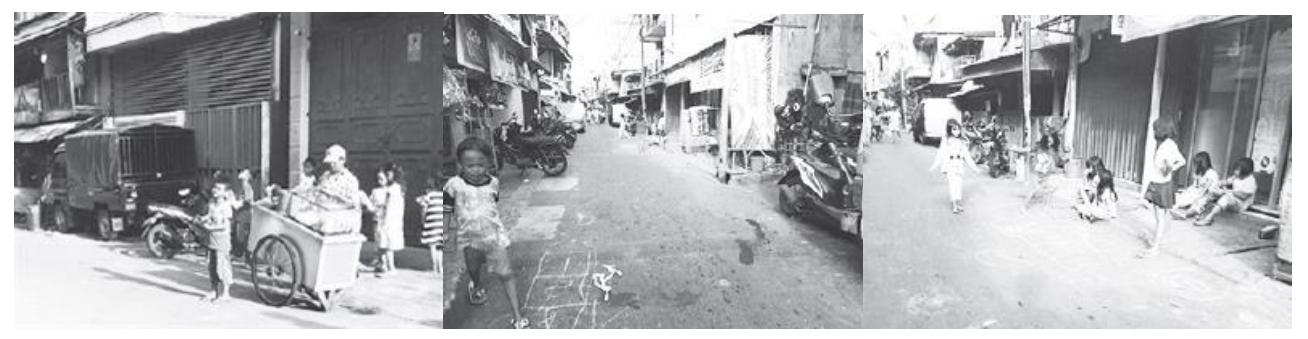

Gambar 2. Jalanan sebagai "living room"

Sumber: Penulis, 2020

Meskipun tidak memiliki ruang terbuka umum, Kalianyar memiliki sebuah ruang hijau terbuka yang cukup besar, yaitu sebuah lapangan sepakbola yang dimiliki oleh Persatuan sepakbola Majalengka yang sekarang ditempati oleh Persatuan sepakbola Kalianyar. Lapangan ini hingga sekarang digunakan apabila terjadi kejuaraan Sepakbola antar kampung dan pertandingan lapangan sepakbola lainnya dengan sistem sewa. Pada lapangan tidak ada fasilitas untuk penonton agar dapat menikmati pertandingan yang ada, dan lapangan yang ada, berdasarkan wawancara masyarakat sekitar, mayoritas diisi dan atau disewakan untuk permainan atau pertandingan sepakbola tertutup.

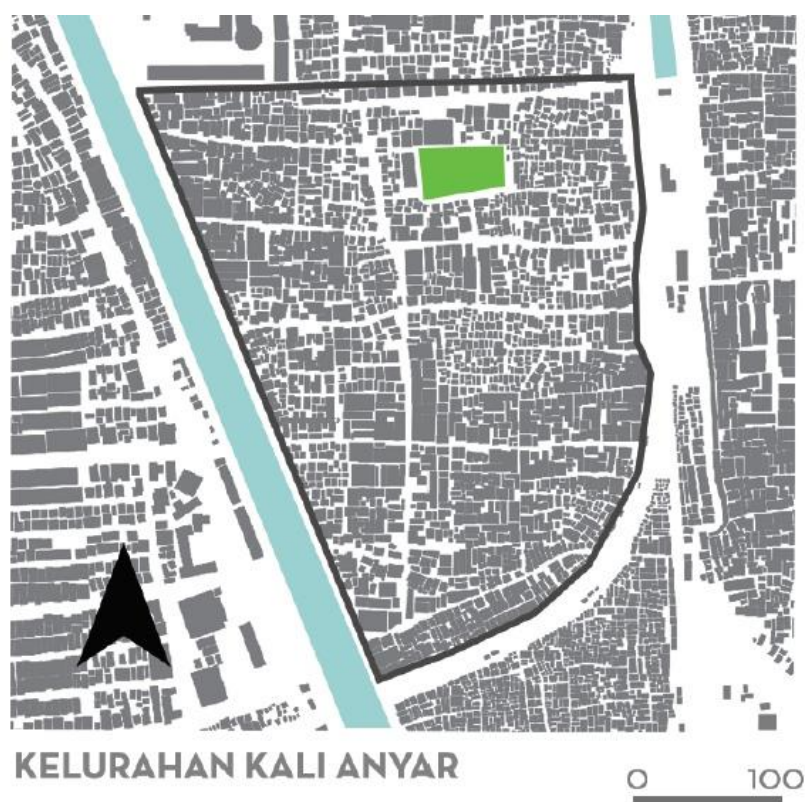

Gambar 3. Titik Hijau pada peta yang menunjukan lapangan terbuka Sumber: Penulis, 2020 


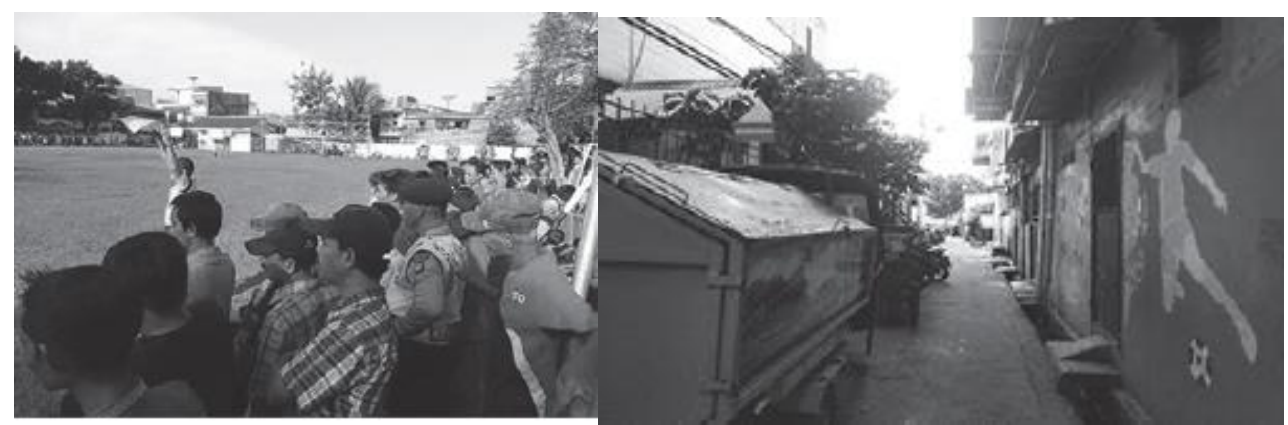

Gambar 4. Suasana Lapangan saat pertandingan (kiri) dan Pintu masuk lapangan (kanan) Sumber: Penulis, 2020

\section{Sintesis / Konsep}

Untuk menyelesaikan permasalahan yang ada, dapat dihadirkan sebuah media penghubung ke dalam lapangan, yang berfungsi pula sebagai penunjang, dan terintegrasi dengan jalan, dalam bentuk sebuah tribun penonton, yang dilengkapi dengan fasilitas umum agar dapat menjadikan lapangan sebagai sebuah ruang terbuka umum hijau dengan fungsi fleksibel yang dapat dinikmati semua kalangan, alhasil sirkulasi pedestrian pada proyek ini merupakan bagian krusial Untuk menggantikan dan menambah peran jalan sebagai ruang publik yang lebih teratur agar tercipta koneksi dan ruang pendukung yang informal terhadap lapangan. Hal ini, secara teori dapat menghemat ruang yang cukup besar dengan memanfaatkan sebuah ruang yang telah hadir.
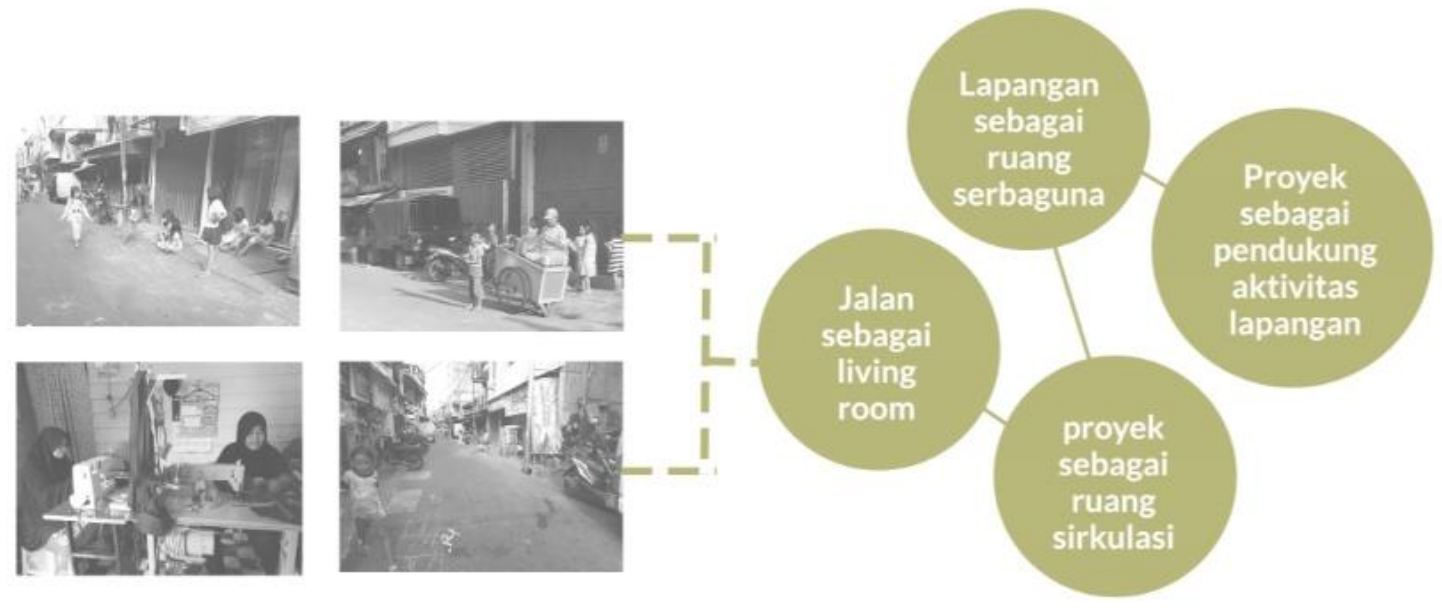

Gambar 5. Diagram Konsep "jalan sebagai ruang" Sumber: Penulis, 2020

Fase pembangunan proyek dapat pula menjadi sebuah solusi dari kurangnya ruang hijau yang ada di daerah ini, dengan dimulainya penanaman pohon bambu, yang dapat tumbuh sangat cepat, dapat tercipta ruang hijau yang secara spontan dapat langsung digunakan baik ruang maupun hasilnya oleh masyarakat. Beberapa dari bambu hidup ini pun diolah menjadi ruang terdesain berupa ruang serbaguna outdoor yang dapat dipakai oleh masyarakat. Tahap berikutnya dibangun pengolahan kayu yang ada untuk menciptakan bangunan dan berbagai properti lainnya sebagai penunjang lapangan seperti lomba burung dara, serta untuk meningkatkan perekonomian warga dengan mengolah dan menjual hasil alam yang ada. 


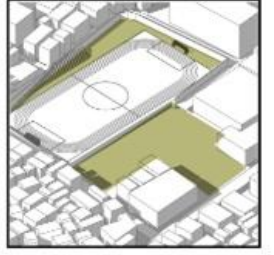

PEMBANGUNAN POHON

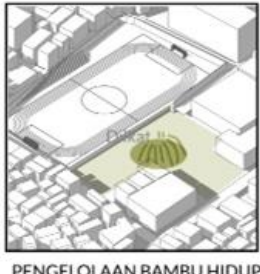

PENGELOLAAN BAMBU HIDUP

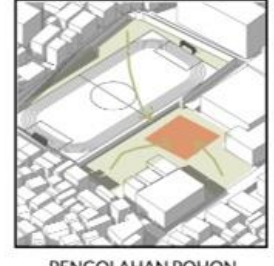

PENGOLAHAN POHON

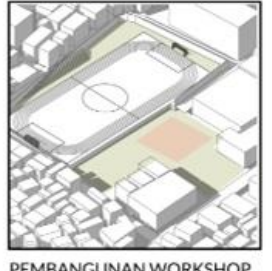

PEMBANGUNAN WORKSHOP

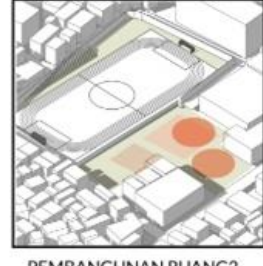

PEMBANGUNAN RUANG2

Gambar 6. Diagram llustrasi Konsep Pembangunan

Sumber: Penulis, 2020

- Sebagai ruang kolektif Masyarakat

Sebagai Pembentuk Jiwa Arsitektur Sebagai daerah padat dan gersang, ruang hijau dapat menjadi sebuah ruang aktif baik pasif dalam memecahkan masalah yang ada akibat isu diatas.

" pohon sebagai penjernih udara

* pohon sebagai ruang rekreasi

+Alam sebagai ekosistem baru
-Sebagai penghubung ruang luar dan lapangan

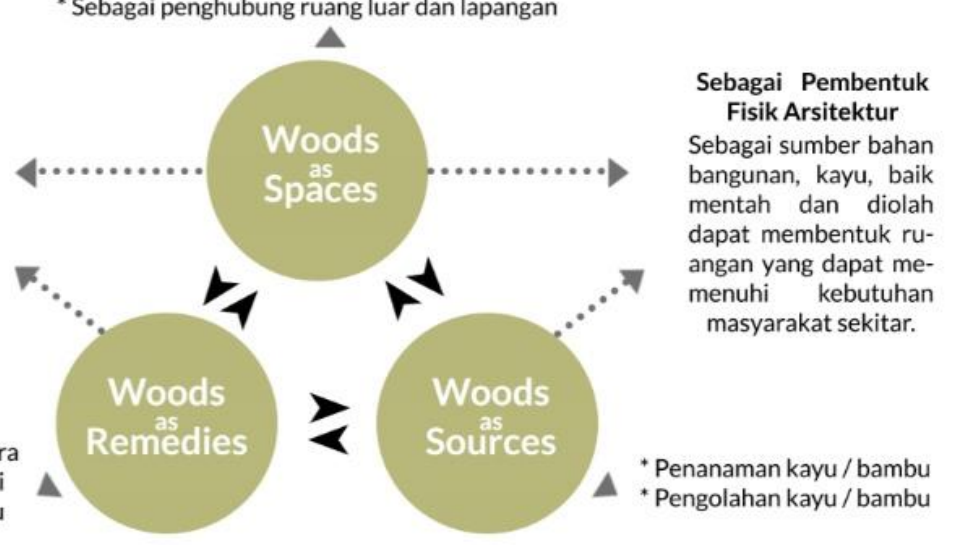

Gambar 7. Diagram Konsep pembangunan berdasarkan alam

Sumber: Penulis, 2020

\section{Program Kegiatan}

Aktivitas dan program di proyek disusun dan dirancang untuk mendukung kegiatan di lapangan. Fungsinya antara lain memberikan ruang jalan untuk memberikan aktivitas, membuat ruang sesuai hobi dan aktivitas di kawasan yang telah ada. Contohnya hobi burung dara, permainan jalanan, Serta pemberian ruang yang sulit didapatkan yaitu ruang bermain hijau yang dilengkapi ruang perpustakaan mini sebagai edukasi tentang hijau.

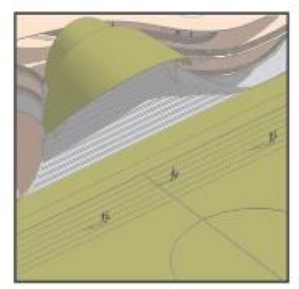

TRIBUN MENONTON, JOG-

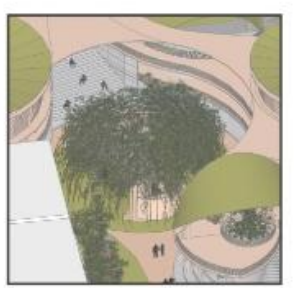

RUANG NOBAR, RUANG HIJAU, DAN RUANG BERMAINALAM

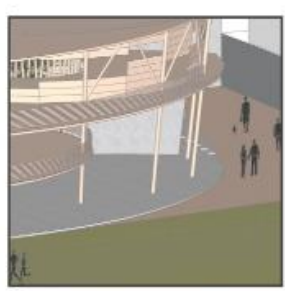

PENGOLAHAN KAYU DAN

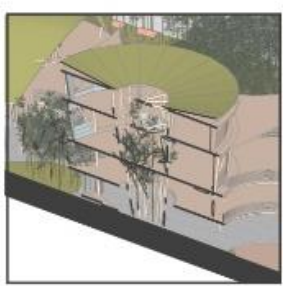

PERPUSTAKAAN MINI, RUANC

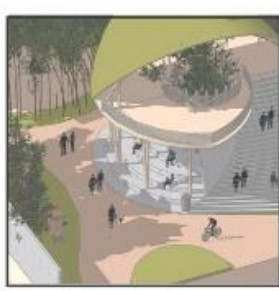

HAWKER CENTER DAN

Gambar 8. Uraian dan Ilustrasi Program bangunan

Sumber: Penulis, 2020

\section{Titik lokasi pembangunan}

Dengan memanfaatkan ruang hijau dan terbuka yang dimiliki lapangan, dimana utara dan selatan terdapat potensi karena berhadapan horizontal dengan lapangan, namun karena terdapatnya berbagai fasilitas penting pada tepi selatan lapangan, kandidat tapak difokuskan pada tepi utara lapangan. 


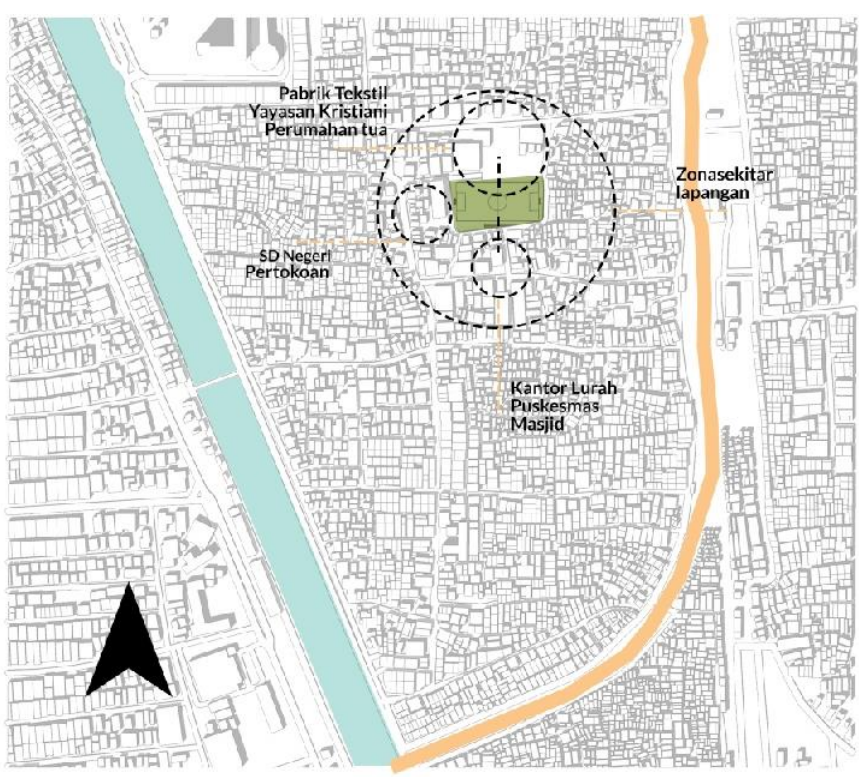

\section{KELURAHAN KALI ANYAR \\ $0 \quad 100$ \\ Gambar 9. Peta Fungsi bangunan sekitar}

Sumber: Penulis, 2020

Lokasi Tapak dipilih dan dibentuk lebih lanjut berdasarkan 3 hal, yaitu koneksinya terhadap lapangan, dimana harus terdapat koneksi langsung dari jalan yang ramah menuju lapangan peruntukan lahan yang dimana digabung terhadap 2, yaitu serbaguna dan rumah tinggal, yang mana mengambil lahan rumah tua 1 lantai dan rumah yang melanggar aturan jumlah lantai, sehingga terbentuklah tapak dibawah dengan luas $2700 \mathrm{M} 2$.

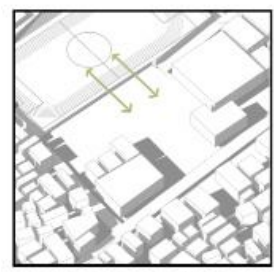

KONEKSILAPANGAN

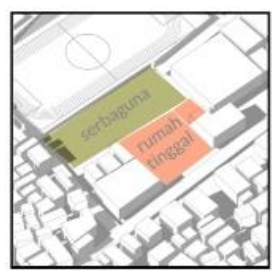

PERUNTUKAN LAHAN

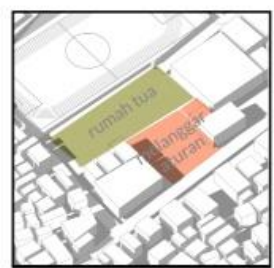

DAPAT DIGUSUR

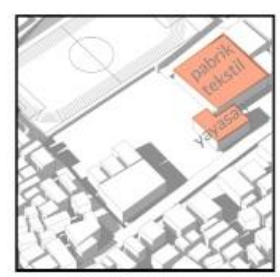

BANGUNAN PENTING

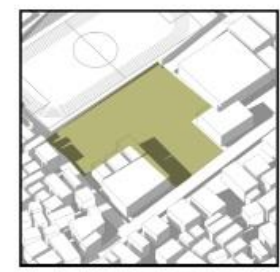

TAPAK TERPILIH

Gambar 10. Diagram Pembentukan Tapak

Sumber: Penulis, 2020

\section{Massa bangunan}

Gubahan massa yang ada mengacu pada prinsip-prinsip seperti tegak lurus pada lapangan, arus sirkulasi pedestrian, zonasi massa yang terbagi berdasarkan target penggunanya yang terbagi 4. Zonasi massa dikategorikan menjadi: umum, ruang yang lebih private, dan ruang pengelola dan pengolahan yang lebih bersifat fungsional, serta ruang terbuka outdoor yang berfungsi mengikat antar massa dan jalur pedestrian yang juga berfungsi sebagai plaza, ruang bermain dan amphiteater. Pada setiap masa juga diberi void, untuk berfungsi menambah cahaya, pengudaraan dan sebagai penopang pada struktur bangunan. 


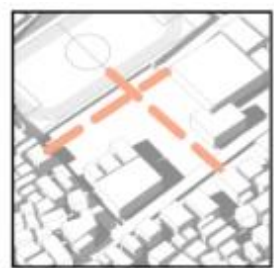

AXIS LAPANGAN

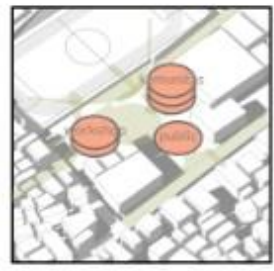

ZONASIMASSA

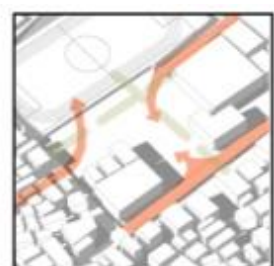

ALUR PEDESTRIAN

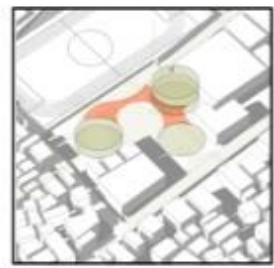

PENGHUBUNG MASSA

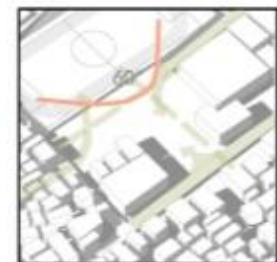

VIEWTRIBUN

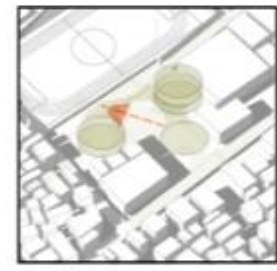

AMPHITHEATER

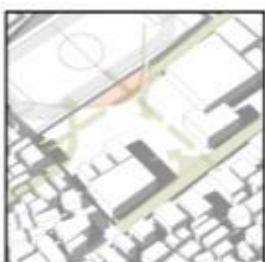

PENEMPATAN TRIBUN

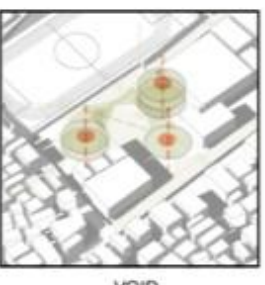

volo

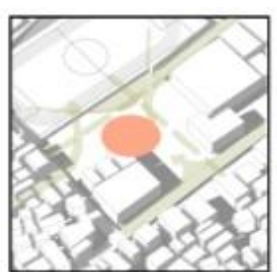

RANTARA PEDESTRIAN

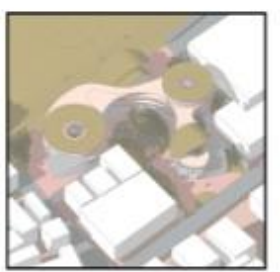

HASILAKHIR

Gambar 11. Diagram Gubahan Massa

Sumber: Penulis, 2020

\section{Material dan fasad bangunan}

Struktur, sebagai rangka dari bangunan, dikonsepkan agar dari bentuk, warna, dipersepsikan sebagai pola dari batang pohon agar terbentuk spasial yang padu antara indoor dan outdoor. Struktur bambu, sebagai salah satu pohon dengan pertumbuhan tercepat, digunakan sebagai media edukasi kepada warga, memberikan kesan hidup dan alami pada bangunan, serta dari segi ekonomi, kecepatan pembangunan dapat dilaksanakan dan sustainability bangunan.

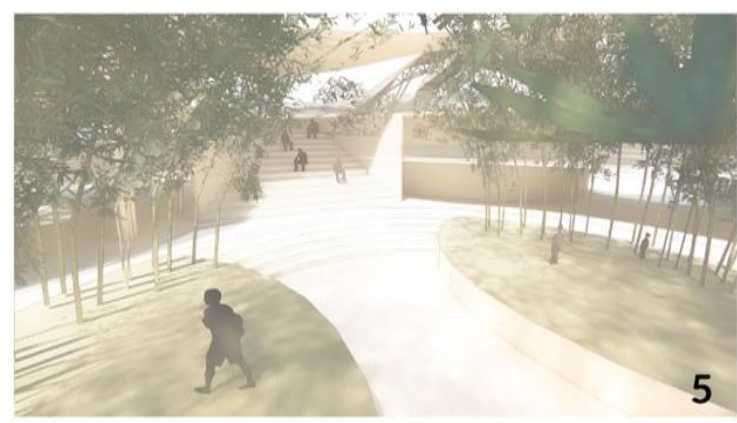

R.HIJAU DAN AMPHITHEATER

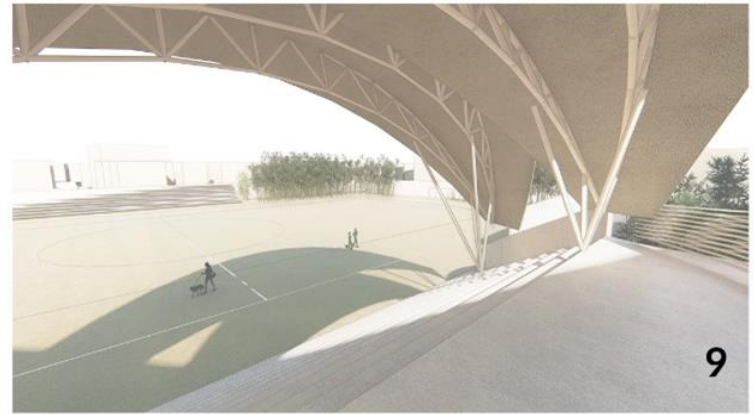

VIEW DARI TRIBUN

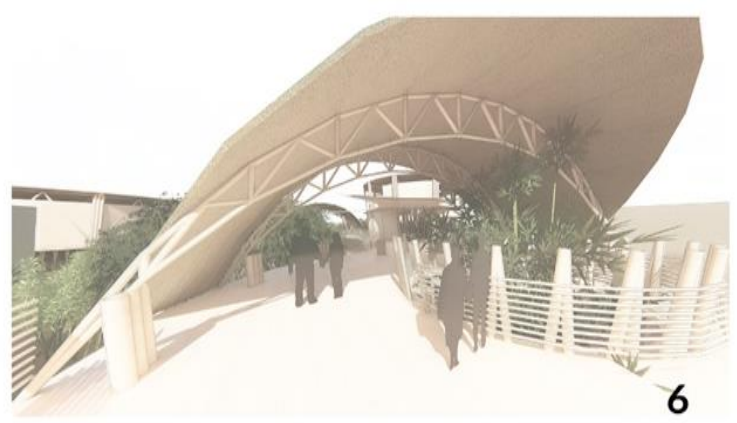

AREANGOBROL

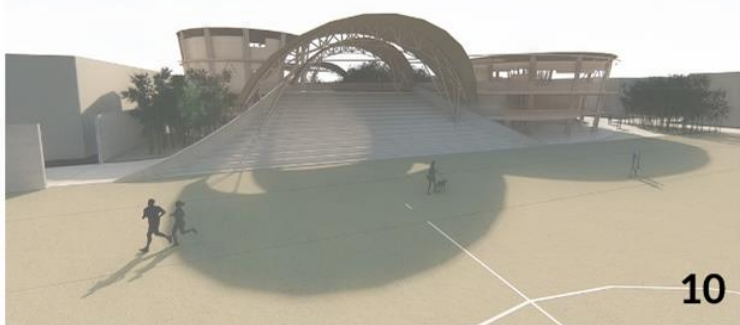

VIEW DARI LAPANGAN

Gambar 12. Perspektif bangunan, memperlihatkan struktur bambu yang digunakan Sumber: Penulis, 2020 


\section{KESIMPULAN DAN SARAN}

\section{Kesimpulan}

Sebuah tribun sepakbola yang pada umumnya merupakan tempat kalangan tertentu, dapat dibentuk menjadi sebuah ruang untuk segala kalangan dengan mempertimbangkan rembesan atau permeabilitas nya dan program yang ditawarkannya. Pada Kalianyar, Jalanan merupakan sebuah ruang sosial utama untuk masyarakatnya, sehingga permeabilitas yang ada pada tribun harus mengutamakan ruang jalan tersebut untuk menjadi bukaan dan ruang pada tribun. Program yang ditawarkan pada lapangan dan bangunan proyek sudah semestinya merespon pada kebutuhan umum, bukan sekedar program yang berkaitan dengan sepakbola saja. Tribun yang ada dapat ditawarkan menjadi sebuah ruang pelengkap dan penghubung masyarakat pada lapangan, sehingga dapat menarik masyarakat umum untuk datang dan membentuk sebuah aktivitas. Dengan minimnya ruang dan biaya, fungsi ruang terdesain dibatasi pada waktu, sehingga dapat mengurangi besaran ruang yang digunakan pada lokasi. Material merupakan elemen arsitektur yang dapat dimanfaatkan untuk memecahkan masalah minimnya ruang hijau pada Kalianyar. Dengan penggunaan struktur dan selubung bambu yang dapat tumbuh cepat dan murah, desain dapat membentuk ruang hijau yang alami dalam jangka waktu cepat namun tetap dapat memiliki fungsi ruang yang diperlukan.

\section{Saran}

Penulis menyarankan studi kelayakan tanah pada lokasi untuk ditanami pohon bambu; berapa banyak bambu yang harus ditanam; berapa lama waktunya untuk mencukupi pembangunan keseluruhan desain yang ada; dan uji kekuatan dan ketahanan struktur bambu dalam menghadapi cuaca dan iklim tropis.

\section{REFERENSI}

Berman, M. G., Jonides, J., Kaplan \& Stephen. (2008). The Cognitive Benefits of Interacting With Nature. Psychological Science.

Bureau of Municipal Research. (1971). Urban Open Space: Luxury Or Necessity?. Toronto: The Bureau.

Francis, J., Giles-Corti, B., Wood, L. \& Knuiman, M. (2012). Creating sense of community: The role of public space.

Fuller, R. A., Irvine, K. N., Devine-Wright, P., Warren, P. H. \& Gaston, K. J. (2007). Psychological benefits of greenspace increase with biodiversity.

Hadiyanto, H. (2020). Faktor Resiko Tuberkulosis pada penduduk urban di Kalianyar, Jakarta Barat.

Hartig, T. (2007). Three steps to understanding restorative environments as health resources. Open Space People Space.

Jeffres. (2009). The Impact of Third Places on Community Quality of Life. Cleveland: Cleveland State University Engaged Scholarship.

Kingsley, M. (2019). Commentary - Climate change, health and green space co-benefits. Health Promotion and Chronic Disease Prevention in Canada.

Maas, J., Verheij, Robert A., Groenewegen, Peter P., Vries, Sjerp, Spreeuwenberg \& Peter (2006). Green space, urbanity, and health: how strong is the relation?.

Mitchell, R. (2013). Is physical activity in natural environments better for mental health than physical activity in other environments?. Social Science \& Medicine.

Myers, M (1975). Decision Making in Allocating Metropolitan Open Space: State of the Art.

Oldenburg, R. (1991). The great good places Cafes, Coffee Shops, Community Centers, Beauty Parlors, General Stores, Bars, Hangouts, and How They Get You Through the Day. New York: Paragon House.

Pemerintah Kota DKI Jakarta (2011). Rencana tata ruang DKI Jakarta 2011-2030. 
Pps.org. (2016). You Asked We Answered: 6 Examples of what makes a great public space. Diunduh 10 Februari 2019, <https://www.pps.org/article/you-asked-we-answered-6examples-of-what-makes-a-great-public-space.

Shishegar, N. (2013). The Impact of Green Areas on Mitigating Urban Heat Island Effect: A Review. The International Journal of Environmental Sustainability.

Thompson, C. W. (2013). Activity, exercise and the planning and design of outdoor spaces. 